\title{
Correction to: Comparison of the clinical effectiveness and safety between the use of denosumab vs bisphosphonates in renal transplant patients
}

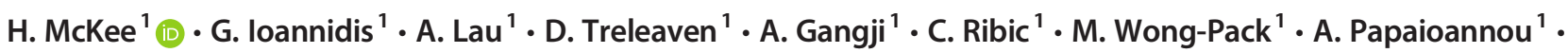 \\ J.D. Adachi ${ }^{1}$
}

Published online: 18 March 2020

(C) International Osteoporosis Foundation and National Osteoporosis Foundation 2020

\section{Correction to: Osteoporosis International} https://doi.org/10.1007/s00198-019-05267-1

The original version of this article, published on 03 January 2020, contained a mistake. An author's name was misspelled. The correct author name reads as follows:

M. Wong-Pack

The original article has been corrected.

The online version of the original article can be found at https://doi.org/ 10.1007/s00198-019-05267-1

H. McKee

mckeeh@mcmaster.ca

1 McMaster University Faculty of Health Sciences, Hamilton, Ontario, Canada 